\title{
Impaired Skeletal Muscle Repair after Ischemia-Reperfusion Injury in Mice
}

\author{
A. Vignaud, ${ }^{1,2,3,4}$ C. Hourde, ${ }^{1,2,3,4}$ F. Medja, ${ }^{1,2,3,4}$ O. Agbulut, ${ }^{5}$ \\ G. Butler-Browne, ${ }^{1,2,3,4}$ and A. Ferry ${ }^{1,2,3,4,6}$ \\ ${ }^{1}$ INSERM, U974, Paris 75013, France \\ ${ }^{2}$ Institut de Myologie, Paris 75013, France \\ ${ }^{3}$ UMR S974, Université Pierre et Marie Curie-Paris6, Paris 75013, France \\ ${ }^{4}$ CNRS UMR 7215, Paris 75013, France \\ ${ }^{5}$ Unité de BFA/CNRS EAC 4413, Université Paris Diderot, Paris 75013, France \\ ${ }^{6}$ Université Paris Descartes, Paris 75006, France
}

Correspondence should be addressed to A. Ferry, arnaud.ferry@upmc.fr

Received 18 December 2009; Accepted 2 March 2010

Academic Editor: Henk L. M. Granzier

Copyright ( $) 2010$ A. Vignaud et al. This is an open access article distributed under the Creative Commons Attribution License, which permits unrestricted use, distribution, and reproduction in any medium, provided the original work is properly cited.

\begin{abstract}
Ischemia/reperfusion (IR) injury can induce skeletal muscle fibre death and subsequent regeneration. By 14 days, absolute and specific maximal forces and fatigue resistance in ischemic/reperfused soleus muscles were still reduced $(-89 \%,-81 \%$, and $-75 \%$, resp.) as compared to control muscles $(P<.05)$. The decrease of these parameters in ischemic/reperfused muscle was much greater than that of myotoxic injured muscles $(-12 \%,-11 \%$, and $-19 \% ; P<.05)$. In addition, at 14 days ischemic/reperfused muscle structure was still abnormal, showing small muscle fibres expressing neonatal myosin heavy chain and large necrotic muscle fibres that were not observed in myotoxin treated muscles. By 56 days, in contrast to myotoxin treated muscles, specific maximal force and muscle weight of the ischemic/reperfused muscles did not fully recover $(P<.05)$. This differential recovery between ischemic/reperfused and myotoxin treated muscles was not related to the differences in the initial cell death, loss of satellite cells after injury, expression of growth factors (IGF1, IGF2..), or capillary density in regenerating muscles. In conclusion, our results demonstrate that IR injury in mice induces long term detrimental effects in skeletal muscles and that the recovery following IR injury was delayed for yet unknown reasons as compared to myotoxic injury.
\end{abstract}

\section{Introduction}

Restoration of blood flow after a period of ischemia causes ischaemia-reperfusion injury (IR). IR injury is a serious clinical problem that occurs in many diseases (myocardial infarction, trauma, tourniquet application as well as in certain neuromuscular diseases). Animal models of IR have been widely used to study the pathophysiology and consequences of IR injury, as well as in cellular and gene therapies. IR injury causes acute vascular leakage, nerve and skeletal muscle damage with consecutive deficit in neuromuscular function [1-3]. Mast cells, neutrophils, inflammatory cytokines, nitric oxide, and reactive oxygen species most likely play a role in the final damage which is observed in the skeletal muscle $[1,3,4]$.
IR injury lasting for more than 2 hours causes extensive skeletal muscle fibre death. Since skeletal muscle is capable of regenerating following injury, subsequent formation of regenerating muscle fibres will occur in the following days. However, it was recently reported that at day 14 following 4 hours of IR injury complete recovery of muscle function had not been achieved [5]. Previous studies have also demonstrated that full recovery of muscle after myotoxin injury can take several weeks [6]. Therefore, it is important to study long-term muscle recovery following IR injury leading to cell death. A few studies have been carried out on longterm muscle recovery following IR injury but most probably they did not induce massive cell death in the models that were used $[7,8]$. In contrast to Carvalho et al. [7], Fish et al. [8] found that full muscle recovery was not reached 42 days 
after 2 hours of ischemia since maximal force production was still reduced in ischemic-reperfused muscles as compared to control muscles in rats.

We report here the results of experiments in mice, aimed at assessing the long-term outcome of IR injury in mouse hind limb muscles. We wanted to determine whether there is a full recovery of muscle function following an IR injury leading to extensive cell death. In order to have a better understanding of the potential effects of IR injury, ischemic/reperfused muscles were compared to myotoxin-treated muscles. The administration of myotoxic agents results in extensive muscle fibre necrosis $[6,9,10]$, without disrupting nerve branches and blood vessels that are elements known to play a major role in muscle repair [11, 12]. Our findings indicate that muscle repair was less efficient following IR injury as compared to that observed after myotoxin injury. These results could provide helpful knowledge in relation to both vascular and neuromuscular diseases.

\section{Materials and Methods}

2.1. Animals. All procedures were performed in accordance with national and European legislations, using young adult rodents (3-6 month old). IR or myotoxic injury was performed on the right legs of male C57BL6 or Myf5-nlacZ (a gift from F. Relaix, INSERM U787, Paris) mice and the tibialis anterior muscles were studied. Animals were anaesthetised with pentobarbital $(60 \mathrm{mg} / \mathrm{kg})$, with supplemental anesthesia as needed. A few hours after IR and myotoxic injury, the animals recuperated a normal mobility.

2.2. Ischemia/Reperfusion Injury. In order to generate unilateral hindlimb ischemia the mice were kept on a heating pad to maintain the body temperature at $37^{\circ} \mathrm{C}$ and the right hindlimbs were made ischemic by placing rubber bands high on the thigh. After 3 hours of ischaemia, the bands were removed. Contralateral (left) legs were left intact and were used as control (nonischemic/reperfused) muscles.

2.3. Myotoxic Injury. Extensive muscle necrosis was created by injecting cardiotoxin, a myotoxic agent, into the muscles $[6,9,10]$. Cardiotoxin (C-3987, Sigma-Aldrich, $10 \mu \mathrm{M})$ was injected into right tibialis anterior in $70 \mu \mathrm{l}$ of normal saline. A needle connected to a microsyringe was inserted near to the distal tendon, pushed up to the proximal tendon, and the cardiotoxin solution was injected into the muscle, the needle being pulled up in order to deliver the solution all along the muscle. Contralateral (left) legs were left intact and were used to provide control (myotoxin untreated) muscles.

2.4. Contractile Measurements. Muscle function was evaluated by the measurement of in situ muscle contraction in response to nerve stimulation, as previously described [13]. At 14, 28, and 56 days after injury, animals were anesthetized (pentobarbital $60 \mathrm{mg} / \mathrm{kg}$ ). During experiments, supplemental doses were given as required to maintain deep anesthesia. The knee and foot were fixed with clamps and pins. The distal tendon of the tibialis anterior (TA) muscles were attached to an isometric transducer (Harvard
Bioscience) using a silk ligature. All data provided by the isometric transducer were recorded and analyzed on a microcomputer, using the PowerLab system (4SP, ADInstruments) and software (Chart 4, ADInstruments). The sciatic nerves were proximally crushed and distally stimulated by a bipolar silver electrode using supramaximal square wave pulses of $0.1 \mathrm{~ms}$ duration. All isometric measurements were made at an initial muscle length of L0 (length at which maximal tension was obtained during the twitch). Responses to tetanic stimulation (pulse frequency $50-143 \mathrm{~Hz}, 500 \mathrm{~ms}$ duration) were successively recorded. At least 1 minute was allowed between contractions. Absolute maximal tetanic forces (P0) were determined. Muscle masses $(\mathrm{m})$ were measured to calculate specific tensions $(\mathrm{P} 0 / \mathrm{m})$. Fatigue resistance $(\mathrm{FR})$ was then determined after a 5 minutes rest period. The muscle was continuously stimulated at $50 \mathrm{~Hz}$ during 2 minutes (submaximal continuous tetanus). The duration corresponding to a force decreased by $20 \%$ was noted FR. Body temperature was maintained at $37^{\circ} \mathrm{C}$ using radiant heat. After contractile measurements, the animals were killed with an overdose of pentobarbital. Muscles were then weighed, frozen in liquid nitrogen, respectively, precooled in isopentane and stored at $-80^{\circ} \mathrm{C}$ until histological and other analyses.

2.5. Histology. Transverse serial frozen sections of TA muscles $(8 \mu \mathrm{m})$ were obtained using a cryostat. Some of the sections were stained with hematoxylin and eosin solution, or Sirius red stain and others were used for immunohistochemistry. For immunohistochemistry, frozen sections were fixed 10 minutes in $2 \%$ paraformaldehyde and incubated overnight in a blocking solution (BSA $1 \%$, sheep serum $1 \%$, triton X-100 0.3\%). Sections were then incubated with either a mouse antibody directed against neonatal MHC, or a rat antibody directed against CD31 (Pharmingen, 553370) in order to measure muscle capillary bed density. The antibody against neonatal MHC was prepared as previously described [14]. The neonatal antibody had previously been shown to react with mouse neonatal heavy chain but not with mouse adult fast MHC [15]. Sections were then washed four times in phosphate-buffered saline (PBS) and incubated with a Cy3 AffiniPure Goat Anti-Rabbit IgG (H+L) (111165-144, Jackson ImmunoResearch), or Alexa Fluor 488 goat anti-rat IgG $(\mathrm{H}+\mathrm{L})$ (A11006, Invitrogen). After four washes in PBS slides were mounted in a mounting solution (mowiol/dabco/hoechst). Images were acquired using a digital camera mounted on a bright-field or a fluorescence microscope.

2.6. Satellite Cell Number. The number of satellite cells was determined using the Myf5-nlacZ heterozygous mice [16], which have a reporter gene encoding nuclear-localizing bgalactosidase (nlacZ), targeted to the Myf5 locus. nlacZ reporter gene- $\beta$-Gal activity was detected histochemically as previously described $[17,18]$. The majority of quiescent and activated satellite cells expressed Myf5 [17, 18].

2.7. Cytokine Antibody Array. RayBio Mouse Cytokine Antibody C Series 1000 kit (RayBiotech) was used for estimating the differential amount of cytokines in pooled protein 
extracts, accordingly to the manufacturer's instructions. Only a selection of cytokines is shown, on the basis of their role in muscle repair. The complete list of cytokines and their full names are available on the manufacturer's web site. Muscle proteins were extracted with Array Lysis Buffer (kit component) and incubated at final concentration of $1 \mu \mathrm{g} / \mu \mathrm{l}$. Each membrane was blocked and incubated with protein extracts. Membranes were washed and then incubated with a biotin-conjugated antibody for 2 hours. Finally, the membranes were washed, incubated with HRPconjugated streptavidin at room temperature for 1 hour and with detection buffer for 1 minute, and exposed to Fuji Film LAS-4000. The intensities of signals were quantified by densitometric analysis with Multi Gauge V 3.0 software and the positive control (biotin-conjugated IgG) was used to normalize the results from each membrane. We performed proteomic analyses using 3 different pooled samples from 4-5 animals/group (ischemic-reperfused muscles, myotoxintreated and untreated muscles).

2.8. Statistical Analysis. Data were analysed using Statistica 5.5 software (StatSoft, Paris, France). Ischemic/reperfused muscles or myotoxin-treated muscles were statistically compared to control muscles using variance analysis. If necessary, subsequent contrast analysis was also performed. Values of IR muscles and myotoxin-treated muscles were also expressed as a percentage of control (normal) muscles, that is, contralateral muscles. Values are means \pm SEM.

\section{Results}

3.1. Effect of IR Injury. At 14 days after IR in contrast to control muscles (Figure 1(a)), ischemic/reperfused muscles exhibited centronucleated muscle fibres of small diameter (regenerating muscle fibres, Figure 1(c)) and "ghosts" that are most likely dead muscle fibres that have not yet disappeared (Figure 1(d)). These observations indicate that IR injury resulted in extensive muscle fibre death, with no apparent survival of muscle fibres and induced insufficient muscle regeneration by day 14 . In order to have a wider insight on the potential effects of IR, ischemic/reperfused muscles were also compared to myotoxin-treated muscles. These muscles exhibited similar extensive muscle damage. However, regeneration was more advanced and more homogeneous since centronucleated muscle fibres filled $>90 \%$ of the muscle cross-section of myotoxin-treated muscles (Figure 1(b)). Fibrosis, based on Sirius Red stainings, was also observed in ischemic/reperfused muscles (Figure 1(h)).

Muscle function also shows drastic changes after IR injury. By 14 days, absolute maximal force (P0, Figure 2), specific maximal force $(\mathrm{P} 0 / \mathrm{m}$, Figure 3$)$, fatigue resistance (FR, Figure 4) and muscle weight (Figure 5) were still markedly reduced in ischemic/reperfused muscles as compared to control muscles $(P<.05)$. The fact that absolute maximal force was reduced by $89 \%$ at day 14 confirmed that none of the muscle fibres had survived to IR injury. In contrast, we found no significant difference between myotoxin-treated muscles and control muscles at day 14 (Figures 2-5). Accordingly, the levels of recovery (\% of control muscles) of absolute maximal force (Figure 2) and specific maximal force (Figure 3 ), fatigue resistance (Figure 4), and weight (Figure 5) in ischemic/reperfused muscles were reduced when compared to myotoxin-treated muscles, by day 14 . By day 28 , the level of recovery of absolute maximal force and weight in ischemic/reperfused muscles was still lower as compared to myotoxin-treated muscles (Figures 2 and 5, $P<.05$ ). By 56 days, ischemic/reperfused muscles fully recovered absolute maximal force (Figure 2) and fatigue resistance (Figure 4). However, specific maximal force (Figure 3) was still reduced in ischemic/reperfused muscles as compared to control muscles, by day 56 $(P<.05)$. This last result was explained by the fact that ischemic/reperfused muscles were heavier by day 56 (Figure $5, P<.05$ ) whereas absolute maximal force was normal (Figure 2).

3.2. Further Analysis of Injured Muscles. To determine whether the difference in muscle recovery between the ischemic/reperfused and myotoxin-treated muscles was related to delayed muscle regeneration, we analysed the expression of neonatal myosin heavy chain (MHC), that is an $\mathrm{MHC}$ isoform expressed at the earlier stage of muscle repair. We found that neonatal MHC was still strongly expressed in ischemic/reperfused muscles (Figure 1(e)) at day 14 but not in myotoxin-treated muscles (Figure 1(f)), confirming delayed muscle regeneration.

It has been previously documented that a reduced blood supply impairs muscle recovery following injury [19]. To test the hypothesis that a reduction in muscle blood supply could explain the difference between ischemic/reperfused and myotoxin-treated muscles, we also analysed muscle capillarity. At day 14, we observed that there was no difference in capillary density between ischemic/reperfused and myotoxin-treated muscles (Figure 6).

We next analysed some of the earlier events in muscle regeneration to try to explain the delayed muscle regeneration observed in the IR group. Since cytokines are known to be involved both in proliferation and differentiation we examined the expression of selected cytokines using a cytokine antibody array that was performed on muscle extracts obtained at day 7 . We did not find any marked difference between these two types of muscle injury concerning the level of growth factors (IGF-1, IGF-2, FGF-2,...) classically involved in muscle repair [20] (Table 1). However, some results did show differences in the 2 types of injured muscles. For example, proteins contributing to angiogenesis (VEGFR1), extracellular matrix remodeling (MMP-2 and MMP-3) were not upregulated in ischemic/reperfused muscles as compared to myotoxin injured muscles, whereas some factors regulating the activation and migration of leukocytes in injured tissues (MIP-1, MIP-2 and MIP-3) and inflammation (sTNF R1 and sTNF R2) were increased in ischemic/reperfused muscles (Table 1).

Muscle fibers are regenerated by the activation and proliferation of satellite cells that fuse together to form myotubes. To determine whether the deficient regeneration observed in ischemic/reperfused muscles was the result of a reduced satellite cell pool, the number of cells expressing 


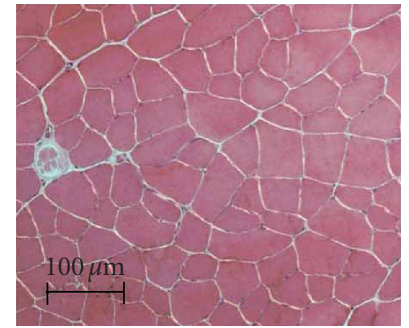

(a)

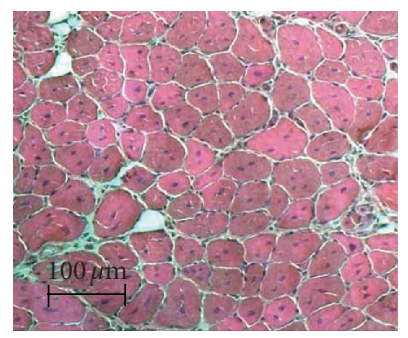

(c)

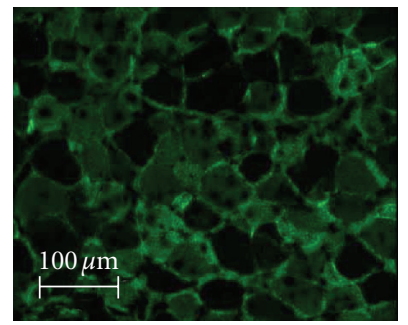

(e)

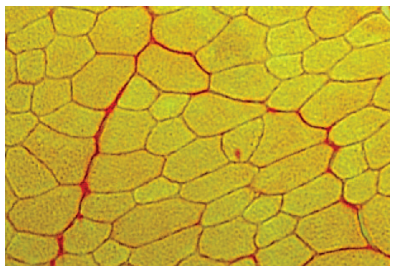

(g)

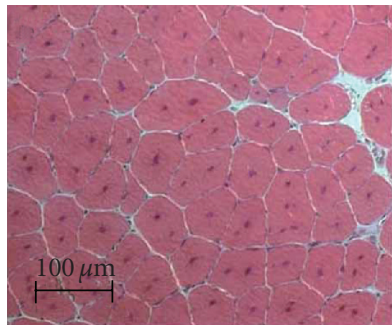

(b)

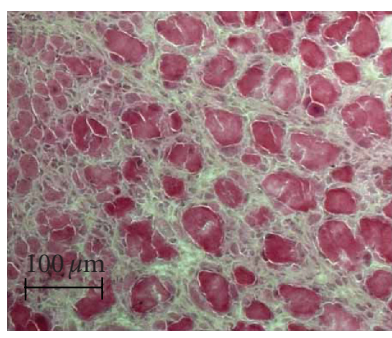

(d)

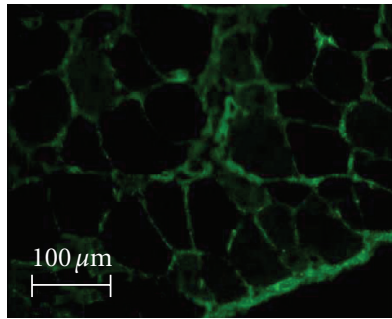

(f)

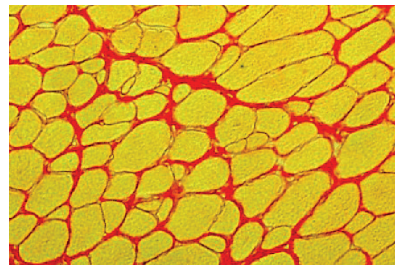

(h)

FIGURE 1: Cross-section of muscles after IR injury and myotoxic injury. Cross-sections 14 days after injury was stained with hematoxylin and eosin solution ((a), (b), (c), (d)) or revealed for neonatal MHC reactivity ((e), (f)). Cross-section 2 months after IR injury were stained with Sirius red stain $((\mathrm{g}),(\mathrm{h}))$. ((a), (g)) control muscles (corresponding to myotoxin-treated muscles); ((c), (d), (e), (h)) Ischaemic/reperfused muscles (IR+); ((b), (f)) myotoxin-treated muscles (MI+).

Myf5 was measured after 3 hours of reperfusion. We found that ischemic/reperfused muscles contained a lower number of Myf5 cells as compared to control muscles $(P<.05$, Figure 7). However the loss of Myf5 cells was similar in ischemic/reperfused and myotoxin-treated muscles muscles (Figure 7).

\section{Discussion}

The aim of this study was to examine the long-term consequence of IR injury on murine hindlimb skeletal muscles. Very little information exists on the rate and on the ultimate extent of muscle recovery following IR injury in this animal model. Our findings indicate that IR injury has a long lasting and detrimental effect on muscle recovery.

Reduced ATP production [7] and mitochondrial dysfunction [2] are the cause of the extensive cellular death after IR injury. Consequently there is a very marked reduction in muscle function observed just after IR $[5,7,21]$. Our results indicate that maximal force and fatigue resistance in ischemic-reperfused muscles were still markedly reduced 14 days after IR injury, in agreement with previous observations $[5,21]$. At this time point, the deficit in absolute maximal force production $(-89 \%)$ can be explained by the decrease in muscle mass and in specific maximal force. This was related to the poor muscle fibre regeneration, since there were regions of the muscle cross section with no regenerating 


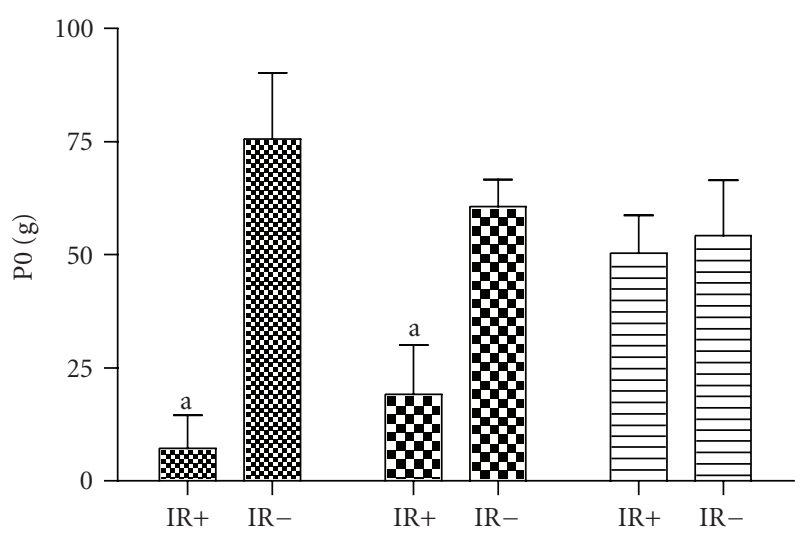

(a)

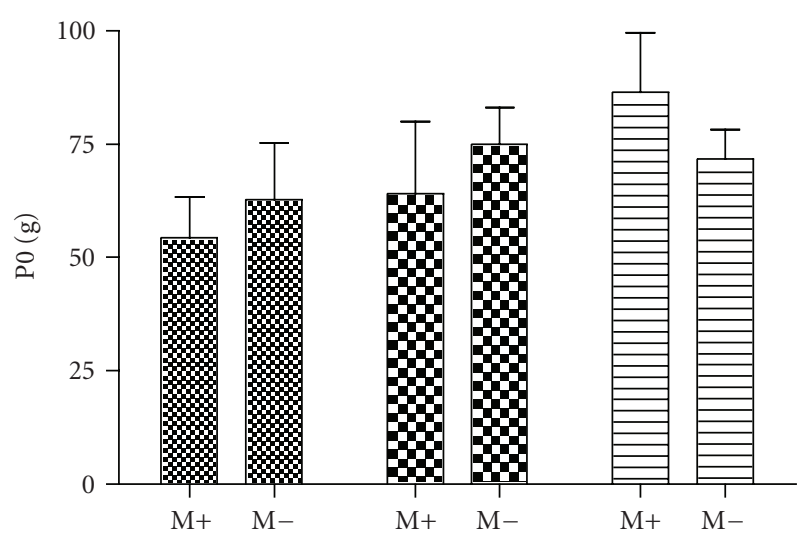

(b)

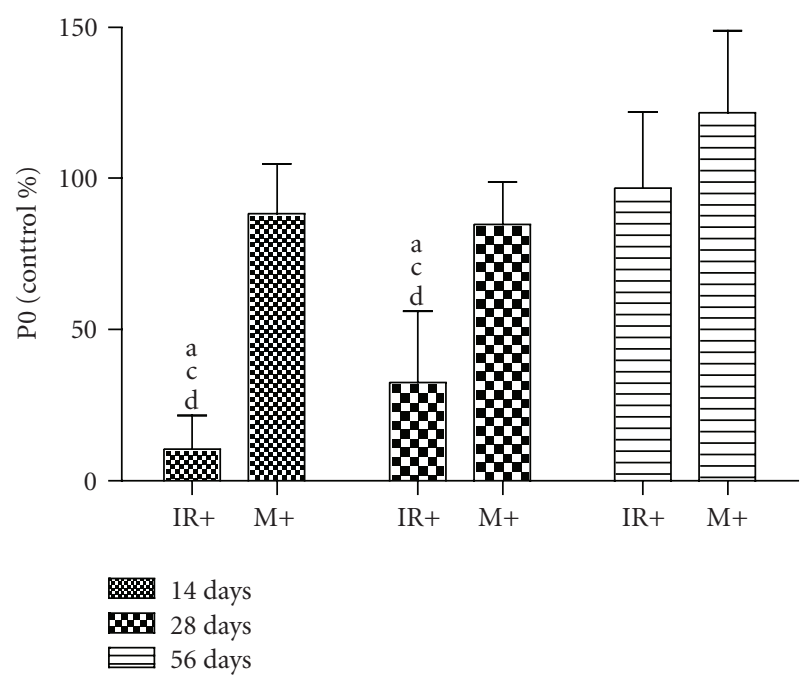

(c)

Figure 2: Maximal tetanic force $\left(\mathrm{P}_{0}\right)$ of muscles after ischemiareperfusion injury and myotoxic injury. Values are means \pm SEM. Number of data per group is 4-6. IR+: ischaemic/reperfused muscles, IR-: control muscles of ischaemic/reperfused muscles, $\mathrm{M}+$ : myotoxin-treated muscles, $\mathrm{M}-$ : control muscles of myotoxintreated muscles. (a) significantly different from control $(P<.05)$, (b) significantly different from 28 days $(P<.05)$, (c) significantly different from 56 days $(P<.05)$, (d) significantly different from $\mathrm{M}+$.

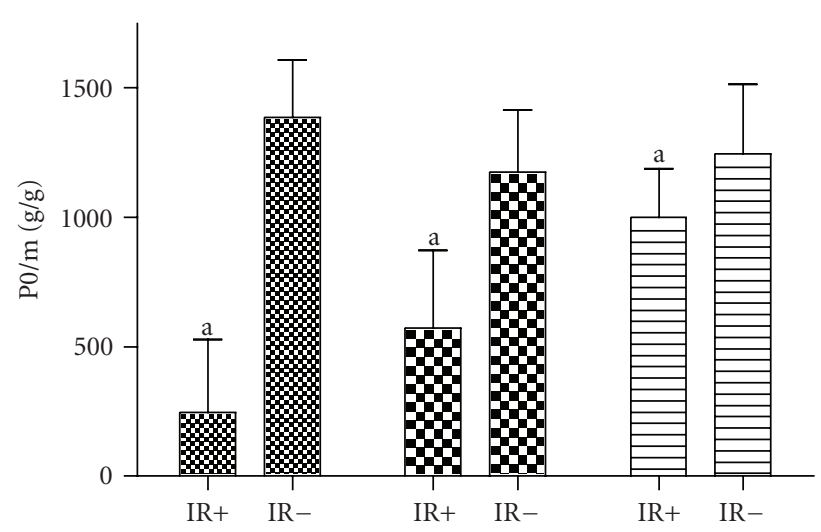

(a)

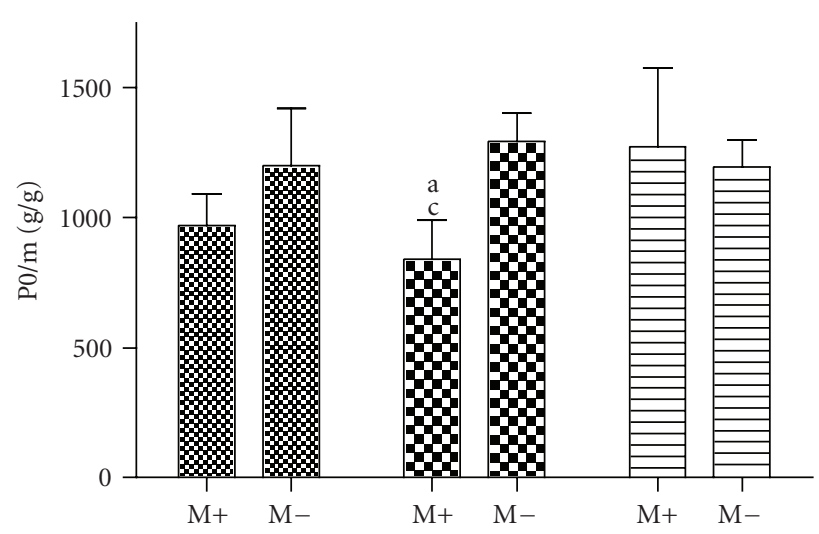

(b)

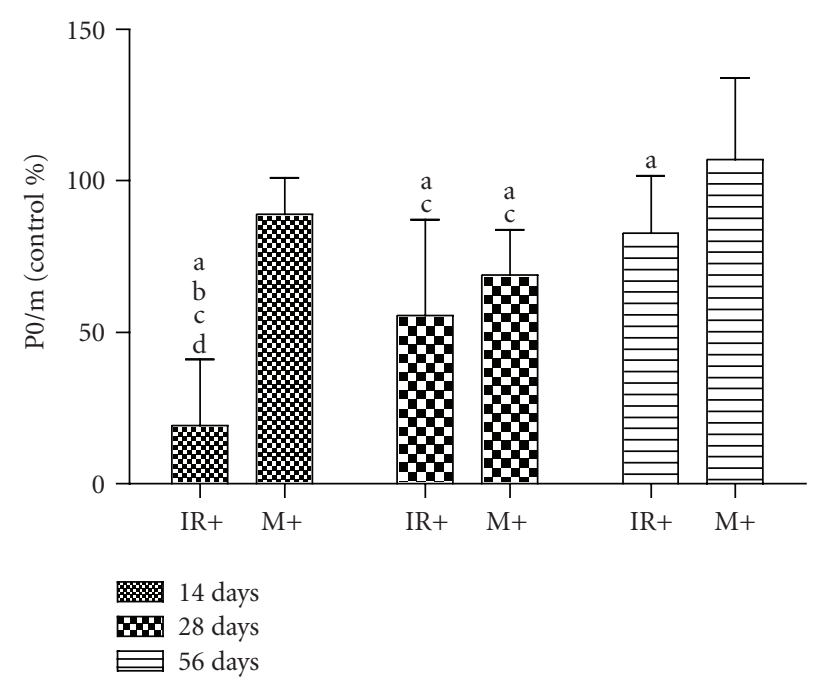

(c)

Figure 3: Specific maximal tetanic force $\left(\mathrm{P}_{0} / \mathrm{m}\right)$ of muscles after ischemia-reperfusion injury and myotoxin injury. Values are means \pm SEM. Number of data per group is 46. IR+: ischaemic/reperfused muscles, IR-: control muscles of ischaemic/reperfused muscles, $\mathrm{M}+$ : myotoxin-treated muscles, $\mathrm{M}-$ : control muscles of myotoxin-treated muscles. (a) significantly different from control $(P<.05)$, (b) significantly different from 28 days $(P<.05)$, (c) significantly different from 56 days $(P<.05)$, (d) significantly different from $\mathrm{M}+$. 


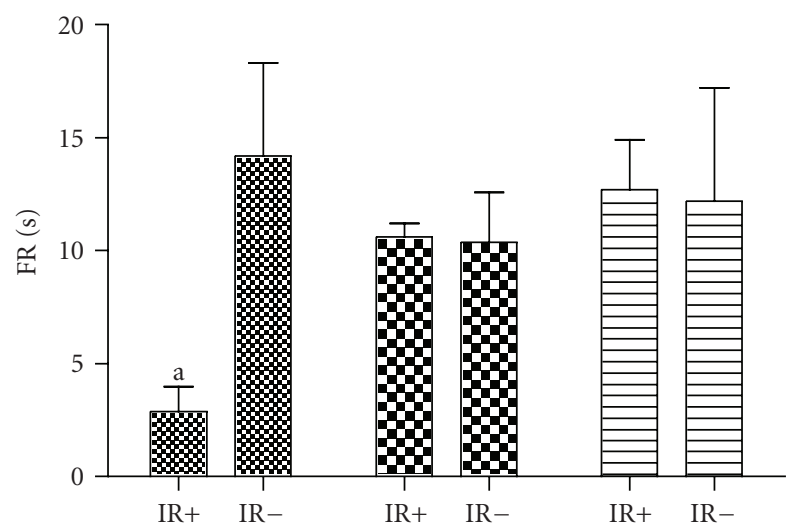

(a)

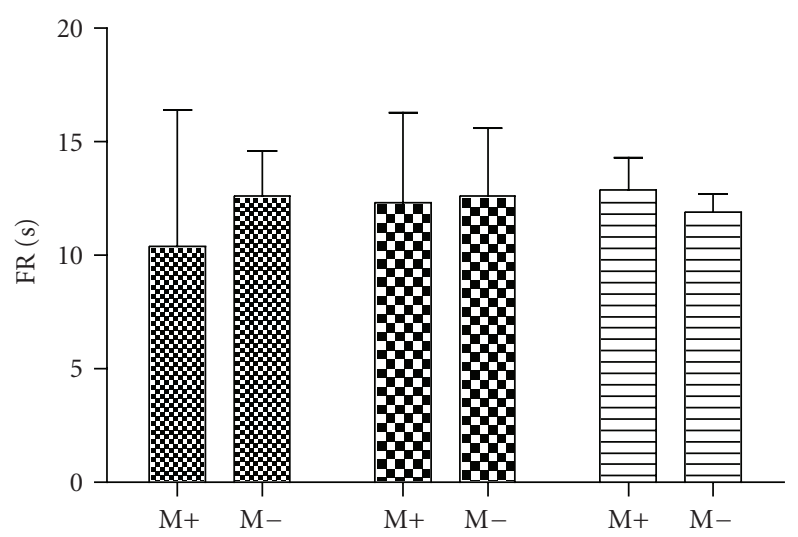

(b)

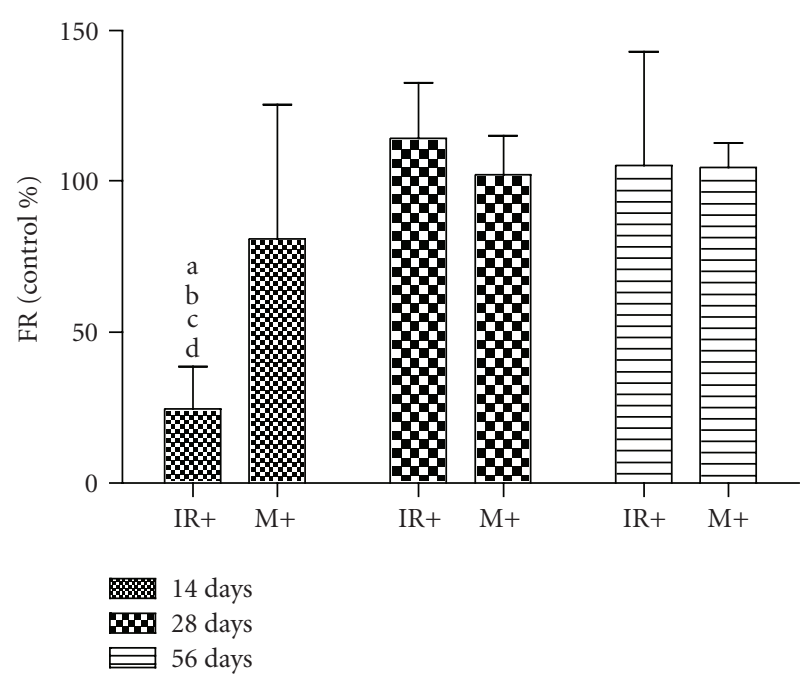

(c)

FIGURE 4: Fatigue resistance of muscles after ischemia-reperfusion injury and myotoxin injury. Values are means \pm SEM. Number of data per group is 4-6. IR+: ischaemic/reperfused muscles, IR-: control muscles of ischaemic/reperfused muscles, $\mathrm{M}+$ : myotoxintreated muscles, $\mathrm{M}-$ : control muscles of myotoxin-treated muscles. (a) significantly different from control $(P<.05)$, (b) significantly different from 28 days $(P<.05)$, (c) significantly different from 56 days $(P<.05)$, (d) significantly different from $\mathrm{M}+$.

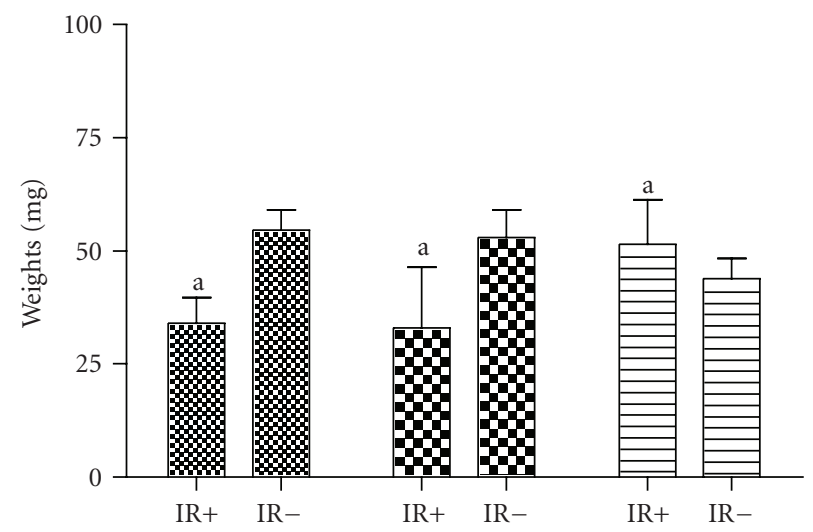

(a)

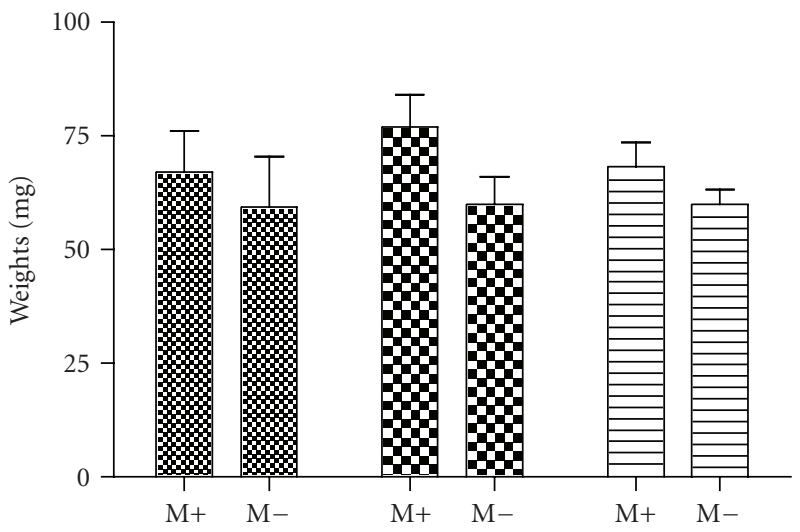

(b)

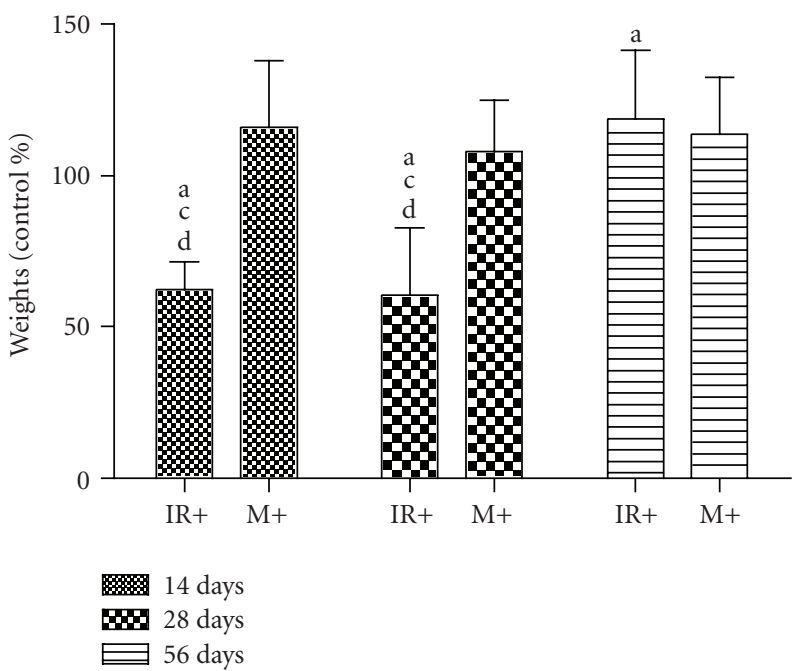

(c)

Figure 5: Muscle weights after ischemia-reperfusion injury and myotoxic injury. Values are means \pm SEM. Number of data per group is 4-6. IR+: ischaemic/reperfused muscles, IR-: control muscles of ischaemic/reperfused muscles, $\mathrm{M}+$ : myotoxin-treated muscles, M-: control muscles of myotoxin-treated muscles-do not you-mean contralateral muscle of myotoxin-treated mice?. (a) significantly different from control $(P<.05)$, (b) significantly different from 28 days $(P<.05)$, (c) significantly different from 56 days $(P<.05)$, (d) significantly different from $\mathrm{M}+$. 


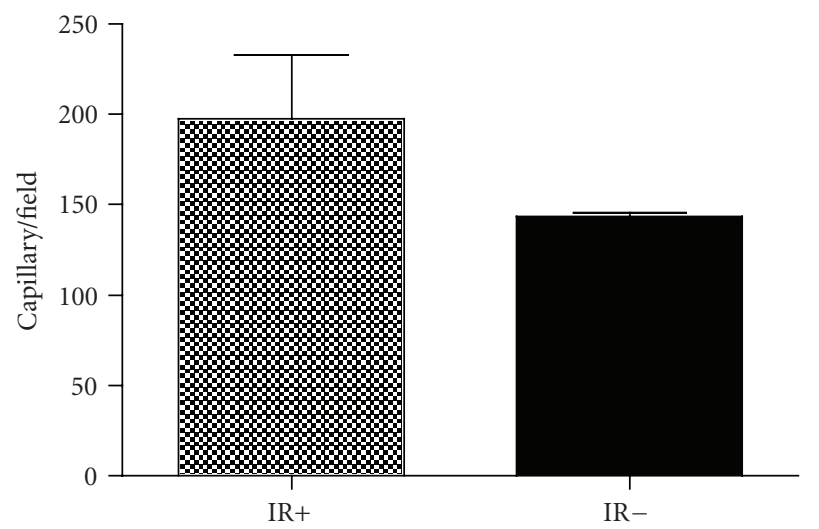

(a)

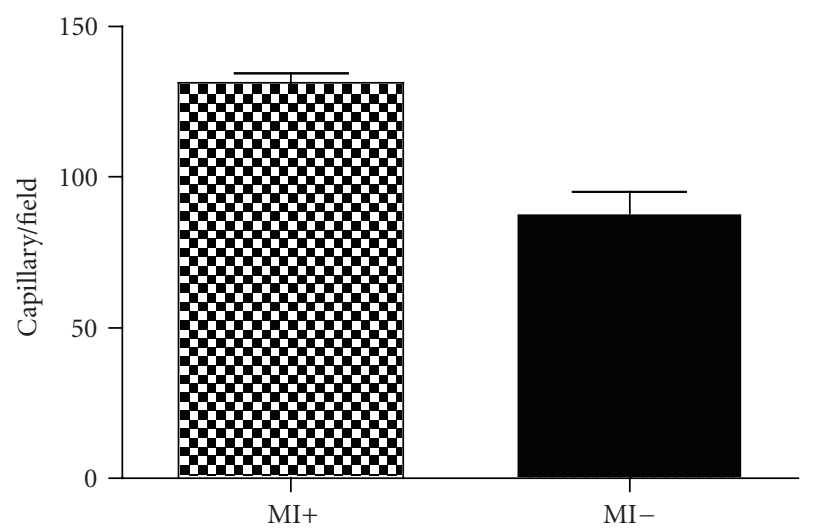

(c)

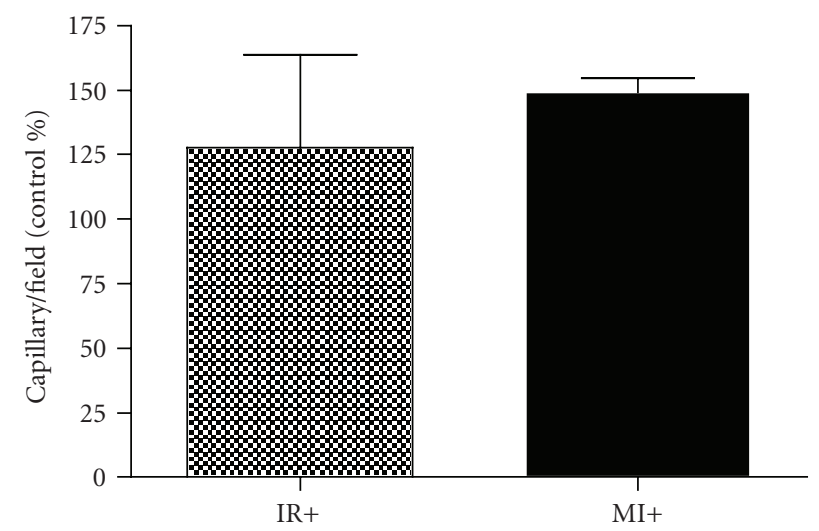

(e)

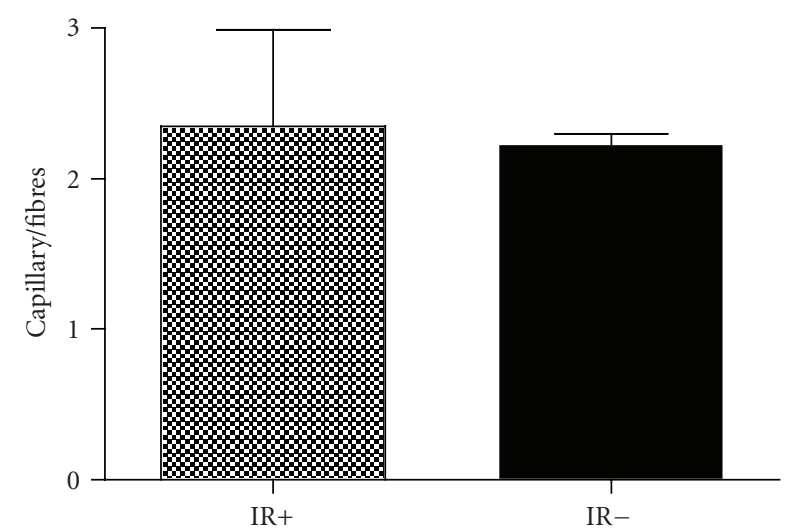

(b)

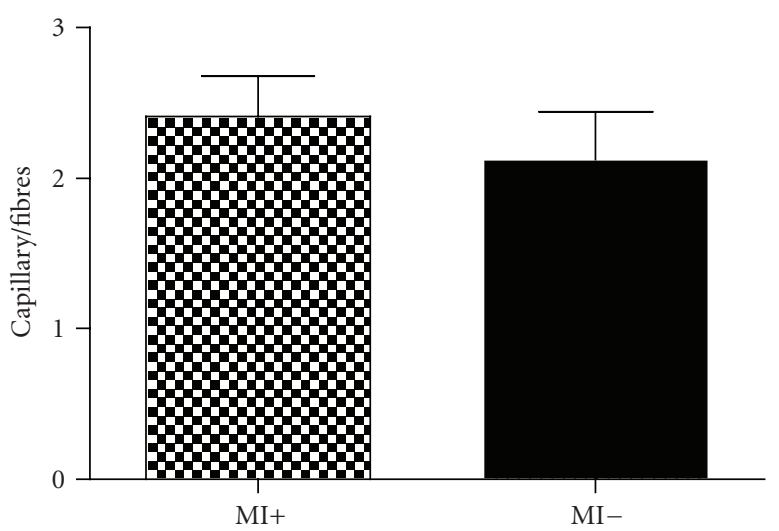

(d)

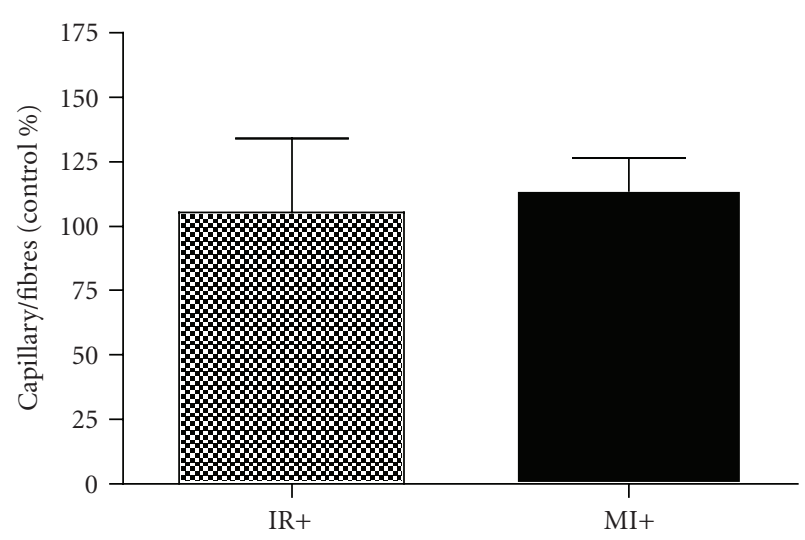

(f)

FIGURE 6: Capillary density 14 days after ischemia-reperfusion injury and myotoxic injury. Values are means \pm SEM. Number of data per group is 3. IR+: ischaemic/reperfused muscles, IR-: control muscles of ischaemic/reperfused muscles, M+: myotoxin-treated muscles, $\mathrm{M}-$ : control muscles of myotoxin-treated muscles.

muscle fibres, resulting in a reduced number of cross-bridges in parallel. Modified neuromuscular transmission cannot be excluded, although a recent study reports that nerve and muscle stimulation resulted in similar force production by day 14 [5].

Full recovery of absolute maximal force and fatigue resistance occurred by days 28 and 56 . However, even at
56 days specific maximal force production was still lower in ischemic-reperfused muscles $(-17.5 \%)$ as compared to control muscles. One reason leading to the long-term deficit in specific maximal force is that ischaemia-reperfused muscles exhibit a lower density of cross-bridges due to increased fibrosis (as shown at days 56). In contrast, myotoxin-treated muscles fully recovered. Therefore our 
TABLE 1: Cytokine expressed in the ischemic-reperfused and myotoxin-treated muscles at day 7 .

\begin{tabular}{|c|c|c|}
\hline & IR+ (\% uninjured $)$ & $\mathrm{MI}+(\%$ uninjured $)$ \\
\hline \multicolumn{3}{|l|}{ Myogenesis } \\
\hline IGF-I & 71 & 63 \\
\hline IGF-II & 43 & 64 \\
\hline IGFBP-2 & 65 & 65 \\
\hline IGFBP-3 & 107 & 122 \\
\hline IGFBP-5 & 109 & 126 \\
\hline IGFBP-6 & 109 & 110 \\
\hline bFGF & 106 & 97 \\
\hline HGF R & 0 & 19 \\
\hline \multicolumn{3}{|l|}{ Angiogenesis } \\
\hline VEGF & 132 & 113 \\
\hline VEGF R1 & 103 & 138 \\
\hline VEGF R2 & 0 & 0 \\
\hline VEGF R3 & 0 & 0 \\
\hline VEGF-D & 0 & 0 \\
\hline \multicolumn{3}{|c|}{ ECM remodelling } \\
\hline MMP-2 & 65 & 153 \\
\hline MMP-3 & 87 & 52 \\
\hline TIMP-1 & 93 & 85 \\
\hline TIMP-2 & 96 & 73 \\
\hline Pro-MMP-9 & 44 & 48 \\
\hline \multicolumn{3}{|l|}{ Chemokines } \\
\hline Fractalkine & 111 & 90 \\
\hline GCSF & 95 & 91 \\
\hline GM-CSF & 91 & 97 \\
\hline KC (IL8) & 129 & 113 \\
\hline MCP1 & 75 & 85 \\
\hline MCP-5 & 72 & 79 \\
\hline MIP-1_ & 136 & 104 \\
\hline MIP-1_ & 196 & 135 \\
\hline MIP-2 & 146 & 119 \\
\hline MIP-3 _ & 153 & 113 \\
\hline MIP-3_ & 132 & 118 \\
\hline RANTES & 119 & 141 \\
\hline \multicolumn{3}{|l|}{ Inflammation } \\
\hline IL-1 b & 117 & 94 \\
\hline IL-6 & 89 & 69 \\
\hline TNF_ & 107 & 92 \\
\hline sTNF RI & 146 & 94 \\
\hline sTNF RII & 135 & 102 \\
\hline
\end{tabular}

results suggest that complete recovery of mouse hindlimb skeletal muscles might never be reached after IR injury, with IR injury reducing the final extent of muscle repair. Thus the long-term consequence of IR injury is that muscle might be heavier $(+18.7 \%)$ to produce a normal level of maximal force, indicating that the functional "quality" of ischemia-reperfused muscle is lower. Interestingly, a deficit in specific maximal force is also observed in the murine model of Duchenne muscular dystrophy, the mdx mice
(-20-25\% [22]). Thus our findings substantiate the concept that myopathy is an aspect of peripheral arterial occlusive disease $[2,3]$.

Another important finding of the present study is that the level of recovery of maximal force, fatigue resistance and muscle weight was delayed in ischaemia-reperfused muscles as compared to myotoxin-treated muscles at day 14 . The differences between ischaemia-reperfused and myotoxic injury were not a result of greater initial injury in the ischaemia-reperfused muscles since all muscle fibers were destroyed by both types of injury. Interestingly, in contrast to myotoxic injury, at 14 days postinjury developmental MHC was not downregulated in ischaemia-reperfused mucles. Therefore our results indicate that muscle regeneration is not only unable to restore normal characteristics but is also delayed following IR injury.

Differential muscle repair between ischemic-reperfused and myotoxin-treated muscles could be explained by different reasons. Satellite cells, local environment, blood vessels and nerve branches are all elements known to play a major role in muscle regeneration. An explanation of our findings could be that part of the satellite cell reservoir, that is, the main source of regenerating muscle fibers was lethally affected by ischemia-reperfusion, resulting in fewer myoblasts, and consequently smaller or less numerous regenerating muscle fibres. In favour of this explanation are data suggesting that muscle recovery increases with the number of satellite cells that escape killing after cryodamage [23]. However we found that the number of Myf5lacZ cells (satellite cells) was similarly reduced by ischemia-reperfusion injury and myotoxic injury. The fact that myotoxic injury can result in satellite cell death was surprising but in agreement with a recent study [24]. Another possibility could be that satellite cell activation proliferation or cell fusion are inhibited by the fact that IR induced an unfavourable environment to muscle repair, such as diabetes [25]. The inflammatory response must be resolved to allow muscle repair [26]. So it is plausible that the reduced muscle repair was the result of a prolonged and combined effect of oxidative stress and inflammation induced by IR injury $[1,3]$. Our cytokine antibody array supports this hypothesis. In contrast to myotoxin-treated muscles, some chemokines and markers of inflammation are still increased in ischemic/reperfused muscles at day 7 . However, the reduced muscle repair that we observed was not caused by a decrease in growth factors that are key players of muscle regeneration (IGF1, IGF-2, FGF-2,...), at least at day 7. Blood supply is also considered to play an important role in muscle repair [11, 12]. This was recently confirmed by a study reporting that arterial peripheral insufficiency decreased muscle recovery after injury [19]. We therefore hypothesised that the reduced blood supply due to microvascular leakage observed after IR [1] explains the reduced muscle recovery after IR injury. Our findings showed that by 14 days there was no reduction in capillarity density. However, our results did not rule out the possibility of a reduced blood supply at earlier stage of muscle regeneration. We noted at day 7 a reduced level of VEGFR1. Finally, it is plausible that terminal nerve damage could be induced by IR injury [27], resulting in 


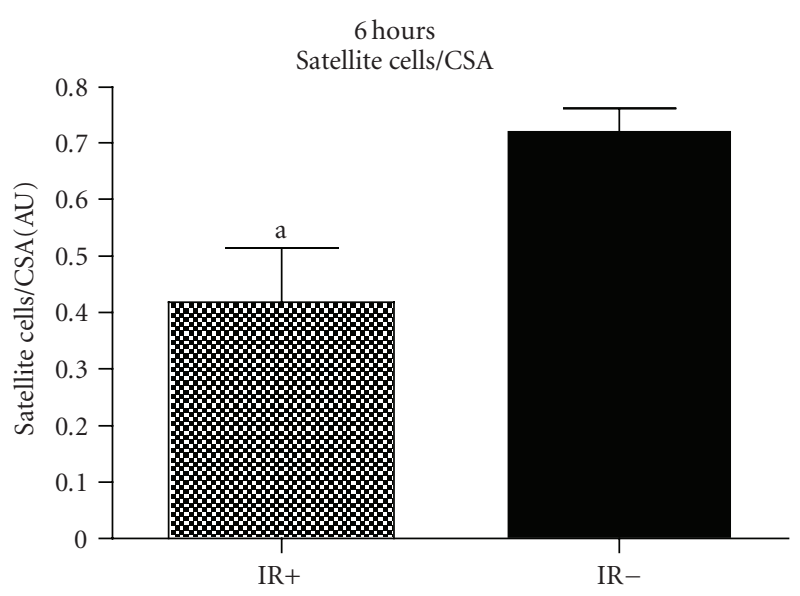

(a)

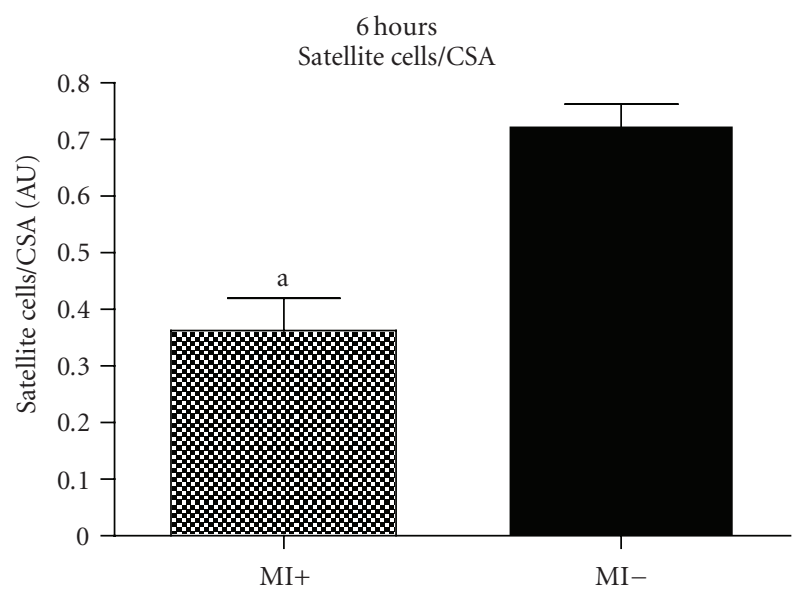

(b)

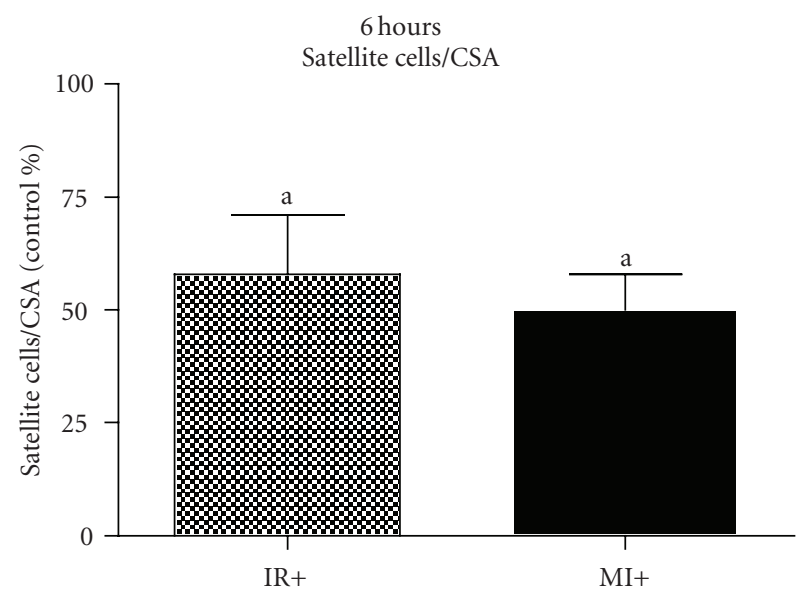

(c)

Figure 7: Number of Myf5 cells 3 hours after ischemia-reperfusion injury and myotoxin injury. Values are means \pm SEM. Number of data per group is 4-6. IR+: ischaemic/reperfused muscles, IR-: control muscles of ischaemic/reperfused muscles, $\mathrm{M}+$ : myotoxintreated muscles, $\mathrm{M}-$ : control muscles of myotoxin-treated muscles. (a) significantly different from control $(P<.05)$. a lower level of neuromuscular activity during the early stage of muscle recovery. It has been reported that although nerves retract from the neuromuscular junction immediately after myotoxin injury there is a very rapid restoration of a functional innervation within $3-5$ days [11]. Neural activity and mechanical loading are essential for correct muscle regeneration after myotoxin injury $[28,29]$.

\section{Conclusion}

In this study we have documented the muscle regeneration that occurs following a period of 3 hours of ischemia in mice. We show that IR injury results in a long-term deficit in muscle function. This was the result of a muscle repair process that was not only delayed but was unable to restore the normal functional characteristics to the regenerated muscle. The lower rate and extent of muscle regeneration after IR injury was not related to a specific loss of satellite cells, nor to a decreased capillary bed density or expression of major growth factors controlling myogenesis. It could however be related to the prolonged inflammation and oxidative stress that does occur after IR. These results confirm the necessity to develop ways to prevent muscle damage induced by IR injury. They should also encourage the research of successful therapies that accelerate muscle repair in the context of vascular deficiency or trauma.

\section{Acknowledgments}

This work has been supported by the Association Française contre les Myopathies, INSERM, University Pierre and Marie Curie, European Commission 6th Framework programme, the Myores Network of Excellence (contract 5111978) and Myoage EU network. The authors would like to thank Paul Ayesteran (UMR 787) for his help during experiments.

\section{References}

[1] D. C. Gute, T. Ishida, K. Yarimizu, and R. J. Korthuis, "Inflammatory responses to ischemia and reperfusion in skeletal muscle," Molecular and Cellular Biochemistry, vol. 179, no. 1-2, pp. 169-187, 1998.

[2] I. I. Pipinos, A. R. Judge, J. T. Selsby, et al., "The myopathy of peripheral arterial occlusive disease. Part 2. Oxidative stress, neuropathy, and shift in muscle fiber type," Vascular and Endovascular Surgery, vol. 42, no. 2, pp. 101-112, 2008.

[3] I. I. Pipinos, S. A. Swanson, Z. Zhu, et al., "Chronically ischemic mouse skeletal muscle exhibits myopathy in association with mitochondrial dysfunction and oxidative damage," American Journal of Physiology, vol. 295, no. 1, pp. R290-R296, 2008.

[4] T. V. Arumugam, I. A. Shiels, T. M. Woodruff, D. N. Granger, and S. M. Taylor, "The role of the complement system in ischemia-reperfusion injury," Shock, vol. 21, no. 5, pp. 401409, 2004.

[5] T. J. Walters, J. F. Kragh, D. S. Kauvar, and D. G. Baer, "The combined influence of hemorrhage and tourniquet application on the recovery of muscle function in rats," Journal of Orthopaedic Trauma, vol. 22, no. 1, pp. 47-51, 2008. 
[6] A. Vignaud, J. P. Caruelle, I. Martelly, and A. Ferry, "Differential effects of post-natal development, animal strain and long term recovery on the restoration of neuromuscular function after neuromyotoxic injury in rat," Comparative Biochemistry and Physiology C, vol. 143, no. 1, pp. 1-8, 2006.

[7] A. J. Carvalho, P. Hollett, and N. H. McKee, "Recovery of synergistic skeletal muscle function following ischemia," Journal of Surgical Research, vol. 59, no. 5, pp. 527-533, 1995.

[8] J. S. Fish, N. E. McKee, W. M. Kuzon, and M. J. Plyley, "The effect of hypothermia on changes in isometric contractile function in skeletal muscle after tourniquet ischemia," Journal of Hand Surgery, vol. 18, no. 2, pp. 210-217, 1993.

[9] R. Couteaux, J.-C. Mira, and A. d'Albis, "Regeneration of muscles after cardiotoxin injury. I. Cytological aspects," Biology of the Cell, vol. 62, no. 2, pp. 171-182, 1988.

[10] A. Vignaud, J. Cebrian, I. Martelly, J.-P. Caruelle, and A. Ferry, "Effect of anti-inflammatory and antioxidant drugs on the long-term repair of severely injured mouse skeletal muscle," Experimental Physiology, vol. 90, no. 4, pp. 487-495, 2005.

[11] J. B. Harris, "Myotoxic phospholipases A2 and the regeneration of skeletal muscles," Toxicon, vol. 42, no. 8, pp. 933-945, 2003.

[12] C. Pastoret and T. A. Partridge, "Muscle regeneration," in Cellular and Molecular Basis of Regeneration, P. A. G. Ferretti, Ed., pp. 309-334, John Wiley and Sons, New York, NY, USA, 1998.

[13] A. Vignaud, C. Hourde, S. Torres, et al., "Functional, cellular and molecular aspects of skeletal muscle recovery after injury induced by snake venom from Notechis scutatus scutatus," Toxicon, vol. 45, no. 6, pp. 789-801, 2005.

[14] G. S. Butler-Browne and R. G. Whalen, "Myosin isozyme transitions occurring during the postnatal development of the rat soleus muscle," Developmental Biology, vol. 102, no. 2, pp. 324-334, 1984.

[15] R. G. Whalen, "Myosin isoenzymes as molecular markers for muscle physiology," Journal of Experimental Biology, vol. 115, pp. 43-53, 1985.

[16] S. Tajbakhsh, E. Bober, C. Babinet, S. Pournin, H. Arnold, and M. Buckingham, "Gene targeting the myf-5 locus with nlacZ reveals expression of this myogenic factor in mature skeletal muscle fibres as well as early embryonic muscle," Developmental Dynamics, vol. 206, no. 3, pp. 291-300, 1996.

[17] J. R. Beauchamp, L. Heslop, D. S. W. Yu, et al., "Expression of CD34 and Myf5 defines the majority of quiescent adult skeletal muscle satellite cells," Journal of Cell Biology, vol. 151, no. 6, pp. 1221-1234, 2000.

[18] R. N. Cooper, S. Tajbakhsh, V. Mouly, G. Cossu, M. Buckingham, and G. S. Butler-Browne, "In vivo satellite cell activation via Myf5 and MyoD in regenerating mouse skeletal muscle," Journal of Cell Science, vol. 112, part 17, pp. 2895-2901, 1999.

[19] C. Hourde, A. Vignaud, I. Beurdy, I. Martelly, A. Keller, and A. Ferry, "Sustained peripheral arterial insufficiency durably impairs normal and regenerating skeletal muscle function," Journal of Physiological Sciences, vol. 56, no. 5, pp. 361-367, 2006.

[20] S. Charge and M. A. Rudnicki, "Fusion with the fused: a new role for interleukin-4 in the building of muscle," Cell, vol. 113, no. 4, pp. 422-423, 2003.

[21] M. D. Woitaske and R. J. M. McCarter, "Effects of fiber type on ischemia-reperfusion injury in mouse skeletal muscle," Plastic and Reconstructive Surgery, vol. 102, no. 6, pp. 2052-2063, 1998.

[22] C. Dellorusso, R. W. Crawford, J. S. Chamberlain, and S. V. Brooks, "Tibialis anterior muscles in $\mathrm{mdx}$ mice are highly susceptible to contraction-induced injury," Journal of Muscle Research and Cell Motility, vol. 22, no. 5, pp. 467-475, 2001.

[23] E. Ghins, M. Colson-van Schoor, and G. Marechal, "The origin of muscle stem cells in rat triceps surae regenerating after mincing," Journal of Muscle Research and Cell Motility, vol. 5, no. 6, pp. 711-722, 1984.

[24] A. Polesskaya, P. Seale, and M. A. Rudnicki, "Wnt signaling induces the myogenic specification of resident $\mathrm{CD} 45^{+}$adult stem cells during muscle regeneration," Cell, vol. 113, no. 7, pp. 841-852, 2003.

[25] A. Vignaud, F. Ramond, C. Hourde, A. Keller, G. ButlerBrowne, and A. Ferry, "Diabetes provides an unfavorable environment for muscle mass and function after muscle injury in mice," Pathobiology, vol. 74, no. 5, pp. 291-300, 2007.

[26] L. Pelosi, C. Giacinti, C. Nardis, et al., "Local expression of IGF-1 accelerates muscle regeneration by rapidly modulating inflammatory cytokines and chemokines," FASEB Journal, vol. 21, no. 7, pp. 1393-1402, 2007.

[27] B. Baxter, T. H. Gillingwater, and S. H. Parson, "Rapid loss of motor nerve terminals following hypoxia-reperfusion injury occurs via mechanisms distinct from classic Wallerian degeneration," Journal of Anatomy, vol. 212, no. 6, pp. 827$835,2008$.

[28] P. Noirez, O. Agbulut, and A. Ferry, "Differential modification of myosin heavy chain expression by tenotomy in regenerating fast and slow muscles of the rat," Experimental Physiology, vol. 85, no. 2, pp. 187-191, 2000.

[29] R. G. Whalen, J. B. Harris, G. S. Butler-Browne, and S. Sesodia, "Expression of myosin isoforms during notexininduced regeneration of rat soleus muscles," Developmental Biology, vol. 141, no. 1, pp. 24-40, 1990. 

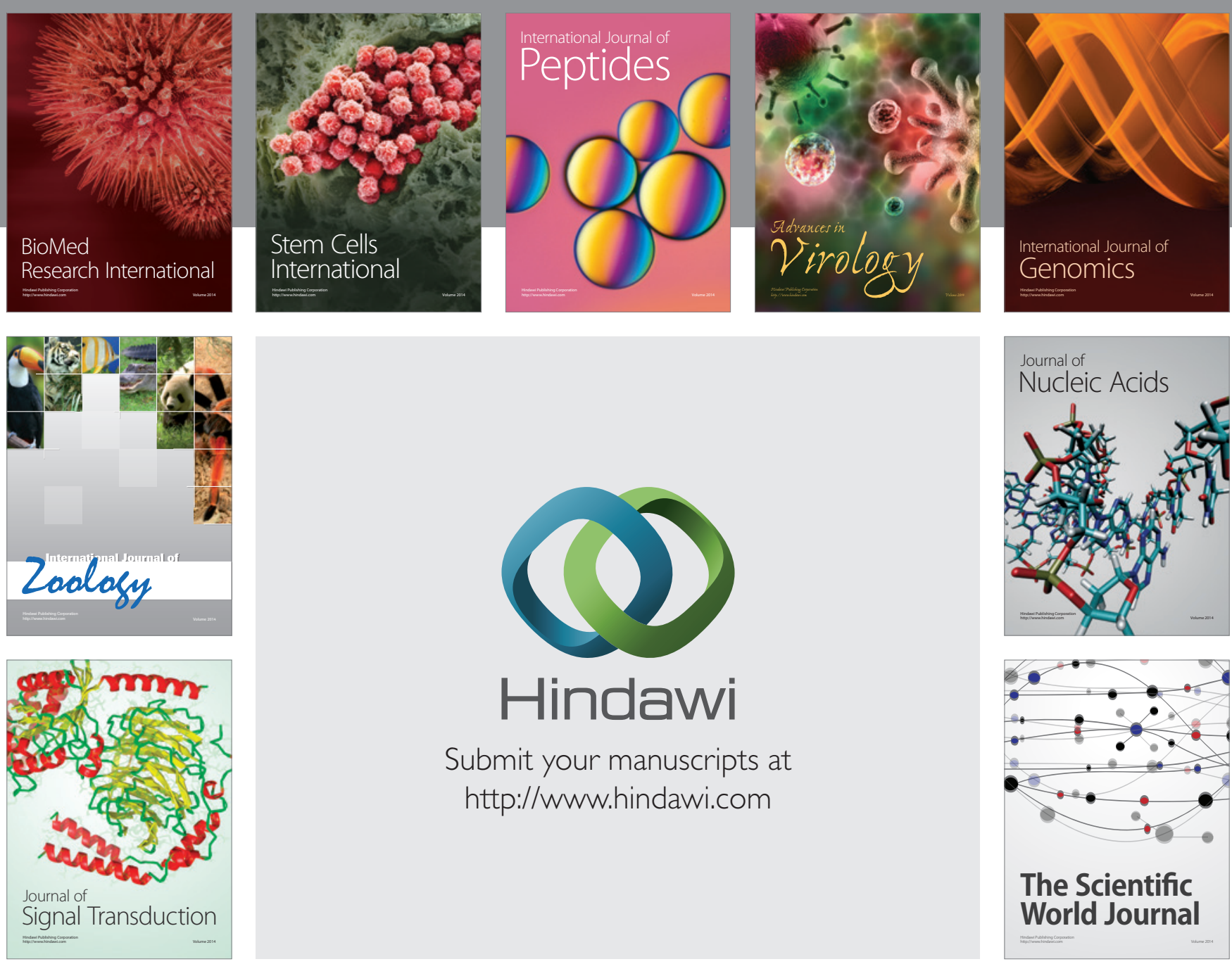

Submit your manuscripts at

http://www.hindawi.com
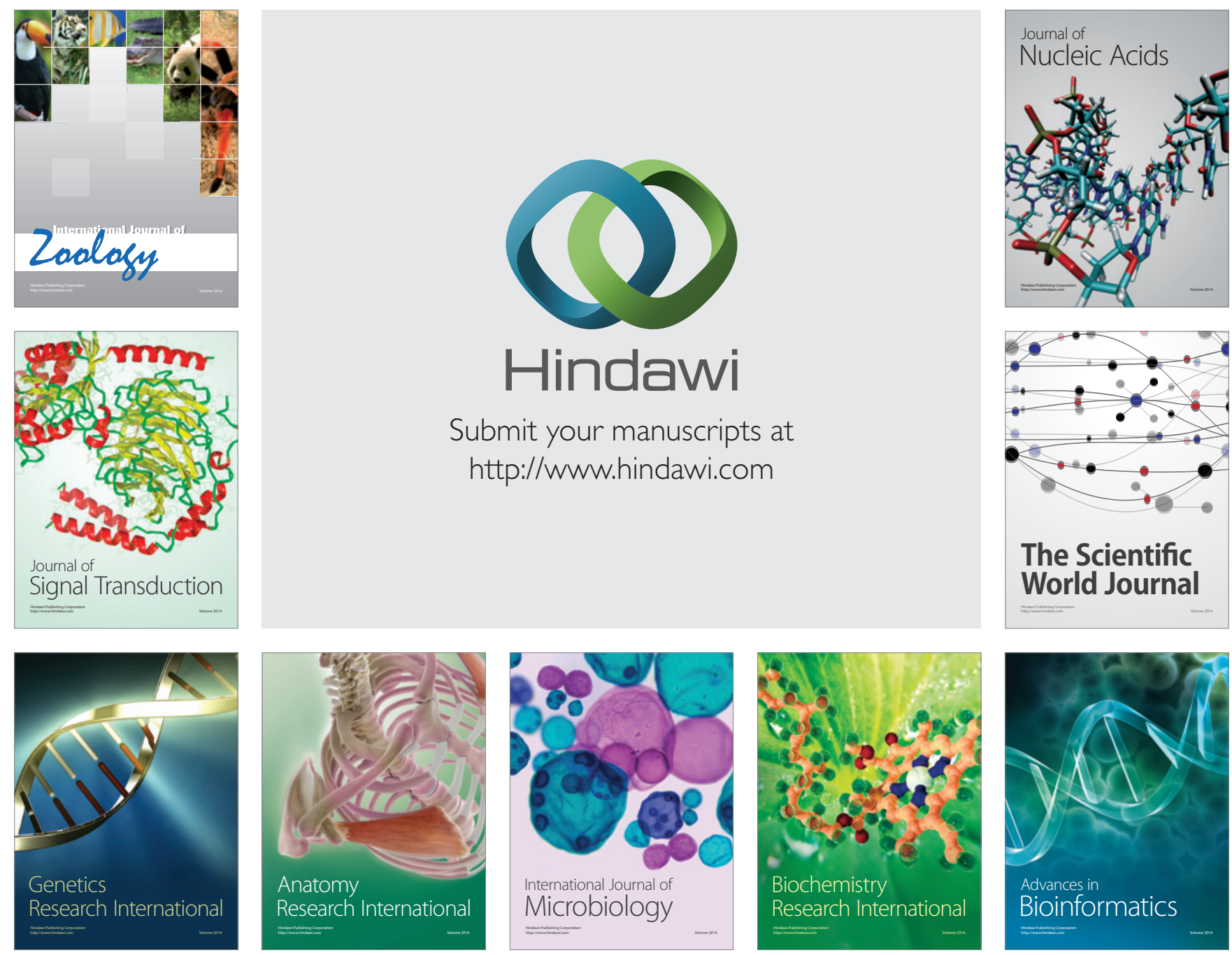

The Scientific World Journal
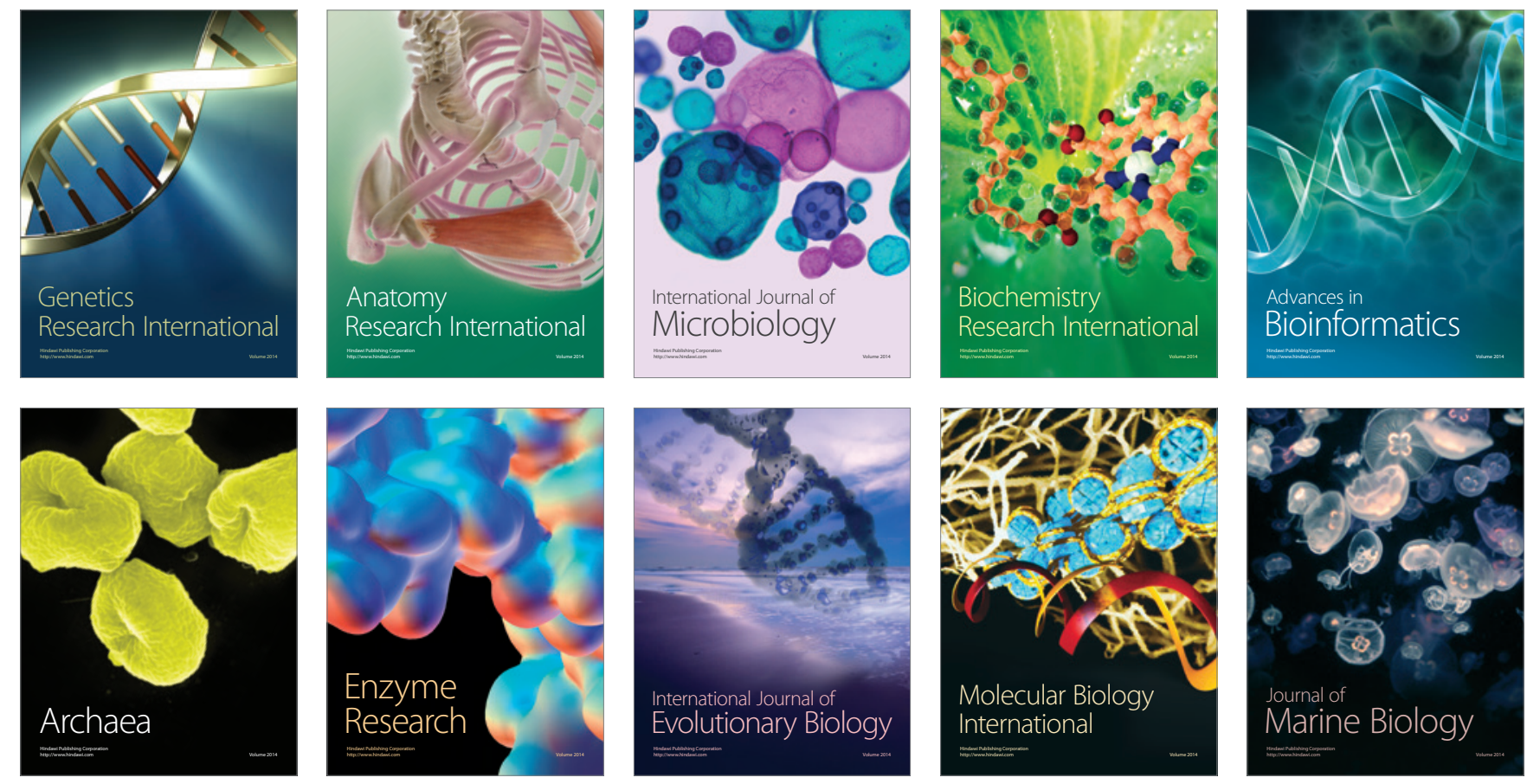